\title{
Mass Spectral Fragmentation Studies of Coumarin-Type Compounds Using GC High-Resolution MS
}

\author{
Viorica Lopez-Avila* and George Yefchak
}

Agilent Technologies, Santa Clara, CA 95051, USA

\begin{abstract}
The present study was undertaken to investigate fragmentation of a set of thirteen coumarins that bear amino-, alkylamino-, alkyl-, fluoroalkyl-groups, and heterocyclic rings, in a high-resolution $(>10,000)$ quadrupole time-of-flight mass spectrometer equipped with an the electron ionization source and interfaced to a gas chromatograph. We have demonstrated how our data processing software is used to generate molecular formulas from high-resolution accurate mass measurements and isotope ratios, and have shown that only with a high-resolution MS can one distinguish between the loss of $\mathrm{CO}, \mathrm{C}_{2} \mathrm{H}_{4}$, or $\mathrm{CH}_{2} \mathrm{~N}$. EI mass spectra are shown for all coumarins tested here, and proposed fragmentation pathways based on the high-resolution MS data are proposed for two coumarins.
\end{abstract}

Keywords: GC High-Resolution MS, GC-QTOFMS, coumarins, molecular formula generation.

\section{INTRODUCTION}

Fragmentation of coumarin under electron ionization (EI) conditions has been described by Porter [1]. Under EI conditions, its mass spectrum exhibits an abundant molecular ion at $\mathrm{m} / \mathrm{z} 146$ and fragment ions at $\mathrm{m} / \mathrm{z} 118$ that have been attributed to loss of $\mathrm{CO}$ from the pyrone ring to form a benzofuran ring. A subsequent loss of $\mathrm{CO}$ gives ion $\mathrm{C}_{7} \mathrm{H}_{6}{ }^{+\cdot}$ at $\mathrm{m} / \mathrm{z}, 90$ and loss of $\mathrm{H} \cdot$ from $\mathrm{C}_{7} \mathrm{H}_{6}{ }^{+}$results in the $\mathrm{C}_{7} \mathrm{H}_{5}{ }^{+}$ion at $\mathrm{m} / \mathrm{z}$ 89. This fragmentation is very similar to that of benzofuran suggesting that the ion at $\mathrm{m} / \mathrm{z} 118$ is a benzofuran radical ion [1]. This fragmentation pathway was verified by Kutney et al. [2] using EI high-resolution mass spectrometry (MS) for a series of methyl-, hydroxyl-, methoxy-, and dimethoxy-coumarins. However, EI fragmentation pathways proposed for several coumarino-(4,3-d) pyrimidine derivatives do not indicate cleavage of $\mathrm{CO}$, or $\mathrm{CO}$ and $\mathrm{H}$ radical, as a major pathway; instead the author [3] proposes a loss of $\mathrm{N}_{2}$, which is unlikely, because the unit-mass resolution of the mass spectrometer used in that study could not distinguish between $\mathrm{N}_{2}$ and $\mathrm{CO}$. Smyth et al. [4, 5] studied the electrospray ionization (ESI) of a series of coumarins including dimeric coumarins using an ion trap and reported that in positive ESI mode coumarin lost a $\mathrm{CO}_{2}$ group from the pyrone ring, and the introduction of an alkyl substituent onto the benzopyran-2-one ring still exhibits the loss of a $\mathrm{CO}_{2}$ group from the pyrone ring.

The present study was undertaken to investigate the EI fragmentation of other coumarin-type compounds in a highresolution (> 10,000) quadrupole time-of-flight mass spectrometer (QTOFMS) equipped with an EI source and interfaced to a gas chromatograph. Table 1 lists the thirteen test compounds and Fig. (1) shows their chemical structures. Various coumarin derivatives that bear alkyl or fluoroalkyl groups, heterocyclic rings (such as benzimidazole and

\footnotetext{
*Address correspondence to this author at the Agilent Technologies, Santa Clara, CA 95051, USA; Tel: (408) 553-2709; Fax: (408) 553-3677;

E-mail: viorica_lopez-avila@agilent.com
}

benzothiazole) on the pyrone ring, and amino-, alkylaminoor quinolizidine on the benzenoid ring, were tested to determine whether the fragmentation pathway is dependent on the nature of the substituent(s) and their relative positions on the pyrone and the benzenoid rings.

The test compounds were first analyzed by gas chromatography (GC) and low-resolution mass spectrometry and their mass spectra were searched against the NIST database. Surprisingly, only five compounds were identified correctly (see Table 1, column labeled "NIST search"). This was attributed to the fact that the remaining compounds were not in the NIST database.

We wanted to find out whether the high-resolution EI spectra were similar to the low-resolution EI spectra in terms of fragmentation patterns, and to generate the molecular formulas of the test compounds from their monoisotopic masses and isotope ratios measured with a research QTOFMS (MS only mode). Likewise, we wanted to generate molecular formulas for the fragment ions, and thus to establish how these compounds fragment under EI conditions.

\section{EXPERIMENTAL}

\subsection{Materials}

Test compounds are available from Sigma Aldrich (St. Louis, MO). Stock solutions of the individual coumarins were made in methylene chloride at concentrations of $1-5 \mathrm{mg} / \mathrm{mL}$. Composite solutions containing all thirteen coumarins listed in Table $\mathbf{1}$ were made in methylene chloride at concentrations of $0.005-0.010 \mathrm{mg} / \mathrm{mL}$.

\subsection{Instrumentation}

\subsubsection{GC-EI Low-Resolution MS Analysis}

GC-MS analyses were performed on an Agilent 6890 GC interfaced to an Agilent 5973 MS equipped with an EI source and autoinjector. Agilent ChemStation software was used for data processing (Agilent Technologies, Santa Clara, 
Table 1. Coumarin Compounds - GC-QTOFMS (EI) Data

\begin{tabular}{|c|c|c|c|c|c|c|}
\hline Compound & $\begin{array}{c}\text { Molecular } \\
\text { Formula }\end{array}$ & NIST Search (Qual) & $\mathbf{M}^{+\cdot}($ Calc $)$ & $\mathbf{M}^{+}($Experim.) & \multicolumn{2}{|c|}{$\begin{array}{l}\text { Mass Error (ppm)/ Score (Rank) } \\
\text { Allowing for "Odd Electron" Ion }\end{array}$} \\
\hline 1. Coumarin & $\mathrm{C}_{9} \mathrm{H}_{6} \mathrm{O}_{2}$ & $\mathrm{C}_{9} \mathrm{H}_{6} \mathrm{O}_{2}(95)$ & 146.0362 & 146.0362 & 0.00 & $96.84(1)$ \\
\hline 2. Coumarin 152 & $\mathrm{C}_{12} \mathrm{H}_{10} \mathrm{~F}_{3} \mathrm{NO}_{2}$ & $\mathrm{C}_{17} \mathrm{H}_{23} \mathrm{NO}(55.5)^{*}$ & 257.0658 & 257.0659 & 0.39 & $95.51(5)$ \\
\hline 3. Coumarin 120 & $\mathrm{C}_{10} \mathrm{H}_{9} \mathrm{NO}_{2}$ & $\mathrm{C}_{10} \mathrm{H}_{9} \mathrm{NO}_{2}(91)$ & 175.0628 & 175.0626 & 1.14 & $96.76(1)$ \\
\hline 4. Coumarin 466 & $\mathrm{C}_{13} \mathrm{H}_{15} \mathrm{NO}_{2}$ & $\mathrm{C}_{13} \mathrm{H}_{15} \mathrm{NO}_{2}(99)$ & 217.1097 & 217.1094 & 1.38 & $95.90(1)$ \\
\hline 5. Coumarin 153 & $\mathrm{C}_{16} \mathrm{H}_{14} \mathrm{~F}_{3} \mathrm{NO}_{2}$ & $\mathrm{C}_{16} \mathrm{H}_{14} \mathrm{~F}_{3} \mathrm{NO}_{2}(95)$ & 309.0971 & 309.0972 & 0.32 & $96.14(4)$ \\
\hline 6. Coumarin 6H & $\mathrm{C}_{15} \mathrm{H}_{15} \mathrm{NO}_{2}$ & $\mathrm{C}_{16} \mathrm{H}_{19} \mathrm{NO}(26.5)^{*}$ & 241.1097 & 241.1095 & 0.83 & $93.52(2)$ \\
\hline 7. Coumarin 102 & $\mathrm{C}_{16} \mathrm{H}_{17} \mathrm{NO}_{2}$ & $\mathrm{C}_{15} \mathrm{H}_{17} \mathrm{~N}_{3} \mathrm{O}(61.3)^{*}$ & 255.1254 & 255.1256 & 0.78 & $96.67(1)$ \\
\hline 8. Coumarin 480D & $\mathrm{C}_{18} \mathrm{H}_{21} \mathrm{NO}_{2}$ & $\mathrm{C}_{17} \mathrm{H}_{17} \mathrm{NO}_{3}(67.7)^{*}$ crotonisine & 283.1567 & 283.1570 & 1.06 & $97.29(1)$ \\
\hline 9. Coumarin 334 & $\mathrm{C}_{17} \mathrm{H}_{17} \mathrm{NO}_{3}$ & $\mathrm{C}_{20} \mathrm{H}_{29} \mathrm{~N}(65.6)$ & 283.1203 & 283.1207 & 1.41 & $96.03(1)$ \\
\hline 10. Coumarin 314 & $\mathrm{C}_{18} \mathrm{H}_{19} \mathrm{NO}_{4}$ & $\mathrm{C}_{18} \mathrm{H}_{19} \mathrm{NO}_{4}(42.6) *$ 6-O-demethylsalutaridine & 313.1309 & 313.1313 & 1.28 & $98.19(1)$ \\
\hline 11. Coumarin 7 & $\mathrm{C}_{20} \mathrm{H}_{19} \mathrm{~N}_{3} \mathrm{O}_{2}$ & $\mathrm{C}_{20} \mathrm{H}_{19} \mathrm{~N}_{3} \mathrm{O}_{2}(91.1)$ & 333.1472 & 333.1471 & 0.30 & $98.13(1)$ \\
\hline 12. Coumarin 30 & $\mathrm{C}_{21} \mathrm{H}_{21} \mathrm{~N}_{3} \mathrm{O}_{2}$ & $\mathrm{C}_{14} \mathrm{H}_{25} \mathrm{~N}_{11}(\mathbf{5 4 . 5})^{*}$ & 347.1628 & 347.1617 & 3.17 & $80.12(4)$ \\
\hline 13. Coumarin 6 & $\mathrm{C}_{20} \mathrm{H}_{18} \mathrm{~N}_{2} \mathrm{O}_{2} \mathrm{~S}$ & $\mathrm{C}_{22} \mathrm{H}_{22} \mathrm{O}_{4}(\mathbf{8 2 . 2})^{*}$ & 350.1083 & 350.1083 & 0.00 & $98.88(1)$ \\
\hline
\end{tabular}

*NIST searched failed to give the correct molecular formula or in case of Coumarin 314 the chemical structure.

CA, USA). Samples were introduced via a $30 \mathrm{~m} \times 0.25 \mathrm{~mm}$ id $\mathrm{x} 0.25 \mu \mathrm{m}$ film thickness HP-5MS capillary column also from Agilent Technologies. The column temperature was ramped from $40^{\circ} \mathrm{C}$ to $150^{\circ} \mathrm{C}$ at $15^{\circ} \mathrm{C} / \mathrm{min}$ and then to a final temperature of $300^{\circ} \mathrm{C}$ at $10^{\circ} \mathrm{C} / \mathrm{min}$, where it was held for 20 min. Helium was used as carrier gas at a flowrate of 1 $\mathrm{mL} / \mathrm{min}$. The injector temperature was $280^{\circ} \mathrm{C}$ and the $\mathrm{GC}$ MS transfer line temperature was $310^{\circ} \mathrm{C}$. The injector was fitted with a double tapered liner and set in splitless mode for $2 \mathrm{~min}$ after the injection (purge flow was $50 \mathrm{~mL} / \mathrm{min}$ ). The electron ionization energy was $70 \mathrm{eV}$ and the electron multiplier detector was set at 1529 V. Spectral data were acquired at a rate of 9 scans/sec and the scanning range was 50 to $600 \mathrm{u}$. The instrument was tuned daily with perfluorotributylamine introduced directly into the EI source.

\subsubsection{GC-EI High-Resolution MS Analysis}

The accurate mass measurements were collected with a research GC-QTOFMS comprising an Agilent GC, an EI source from an Agilent 5975 quadrupole mass spectrometer, and an Agilent 6510 QTOFMS that was upgraded with a 4$\mathrm{GHz}$ data acquisition system. The GC conditions were identical to those described above except for a 1-m heated transfer line. The ionization energy in the EI source was 70 $\mathrm{eV}$. The mass axis was calibrated using seven peaks from perfluorotributylamine, and a background phthalate ion at $\mathrm{m} / \mathrm{z}$ 149.02332, a common contaminant in GC/MS, was used as a real-time reference mass. Perylene- $\mathrm{d}_{12}$ was used as internal standard. An algorithm available in our data processing software allowed us to determine an overall score for each proposed compound by users-selected weighting of the Mass Match score, the Abundance score and the Spacing Match (i.e., mass score is $100 \%$, isotope abundance score is $60 \%$, and isotope spacing score is 50\%). These overall scores were used to determine a ranking order for compound identification. Formula generation was configured to allow use of up to $30 \mathrm{C}, 120 \mathrm{H}, 30 \mathrm{O}, 30 \mathrm{~N}, 5 \mathrm{~S}, 3 \mathrm{Cl}$, and $5 \mathrm{~F}$ atoms and was restricted to results having an "odd electron" (i.e., $\mathbf{M}^{+\cdot}$ ) configuration.

\section{RESULTS AND DISCUSSION}

\subsection{GC - Low Resolution MS}

A GC chromatogram of the thirteen compound mixture is shown in Fig. (2). All compounds are baseline resolved and their elution from the chromatographic column follows the order in which the test compounds are listed in Table 1. The EI low-resolution MS spectra (not shown) exhibit the typical fragmentation patterns of coumarin-type compounds (i.e., loss of two CO groups) and this will be discussed below. Compounds $1,3,4,5$, and 11 were identified correctly using the NIST database search. For the remainder of the compounds, except Compound 10, the NIST search came up with the wrong molecular formulas. For compound 10, the molecular formula was correct in the NIST database search but compound identification as 6-O-demethyl-salutaridine was incorrect.

\subsection{GC-High Resolution QTOFMS}

\subsubsection{Molecular Formula Generation}

Table 1 shows the calculated and experimental $\mathrm{m} / \mathrm{z}$ for the molecular ions of the test compounds, the mass errors (ppm), and the overall scores and ranks for each compound calculated with our software. It is worth noting that all of the mass errors were below $1.41 \mathrm{ppm}$ except for one outlier with a mass error of $3.17 \mathrm{ppm}$. Although the scores of coumarins 152 and 153 were above 95, their ranks were 5 and 4, respectively. This was due to their low Abundance Match scores, indicating that the isotope distribution was slightly off. The low overall score of Coumarin 30 was because of the low Mass Match. Once the molecular formulas were generated for each compound from the accurate mass of the 
<smiles>CN(C)c1ccc2c(C(F)(F)F)cc(=O)oc2c1</smiles>

Coumarin (1)

Coumarin $152(2)$<smiles>Cc1cc(=O)oc2cc(N)ccc12</smiles>

Coumarin 120 (3)<smiles>CCN(CC)c1ccc2ccc(=O)oc2c1</smiles>

Coumarin 466 (4)<smiles>CC(C)c1cc(=O)oc2c3c4c(cc12)CCCN4CCC3</smiles>

Coumarin 480D (8)<smiles>O=c1ccc2cc3c4c(c2o1)CCCN4CCC3</smiles>

Coumarin $6 \mathrm{H}(6)$<smiles>Cc1cc(=O)oc2c3c4c(cc12)CCCN4CCC3</smiles>

Coumarin 102 (7)<smiles>CCOC(=O)c1cc2cc3c4c(c2oc1=O)CCCN4CCC3</smiles>

Coumarin 314 (10)<smiles>CCN(CC)c1ccc2cc(-c3nc4ccccc4[nH]3)c(=O)oc2c1</smiles><smiles>CCN(CC)c1ccc2cc(-c3nc4ccccc4n3C)c(=O)oc2c1</smiles><smiles>CCN(CC)c1ccc2cc(-c3nc4ccccc4s3)c(=O)oc2c1</smiles>

Fig. (1). Chemical structures of test coumarins.

monoisotopic peak, we looked at the number of rings and double bonds $(\mathrm{r}+\mathrm{db})$ especially for those compounds that ranked worse than 2, namely Coumarin 152 , Coumarin 153 , and Coumarin 30, to see if we can eliminate possible formulas that were ranked higher and would correspond to "even electron" fragment ions instead of the "odd electron" molecular ions. For Coumarin 152, which was ranked 5 out of 61 with scores from 99.02 to 41.28 , there were four molecular formulas with higher scores from which we eliminated three as "even electron" ions and retained one: $\mathrm{C}_{6} \mathrm{H}_{12} \mathrm{FN}_{3} \mathrm{O}_{7}$ with $2(\mathrm{r}+\mathrm{db})$. This formula was unlikely to belong to a coumarin-type compound because the degree of unsaturation was too low (specifically, a coumarin-type compound has to have at least two rings and five double bonds for a total of $7(\mathrm{r}+\mathrm{db}))$.

For Coumarin 153, which was ranked 4 out of 100 with scores between 97.92 and 41.46, there were three molecular formulas with higher scores, all of which were "odd electron" ions, and had 5, 9, and $4(\mathrm{r}+\mathrm{db})$, respectively. Formula $\mathrm{C}_{11} \mathrm{H}_{12} \mathrm{FN}_{7} \mathrm{O}_{3}$ with $9(\mathrm{r}+\mathrm{db})$ could belong to a coumarin-type compound but had too many $\mathrm{N}$ and not enough $\mathrm{F}$ atoms (when $\mathrm{F}$ atoms are present in synthetic coumarins they are usually in multiples of three as in $\mathrm{CF}_{3}$ or five as in $\mathrm{C}_{2} \mathrm{~F}_{5}$ ). However, we had a correct identification for this compound from the NIST search and no longer investigated it. 


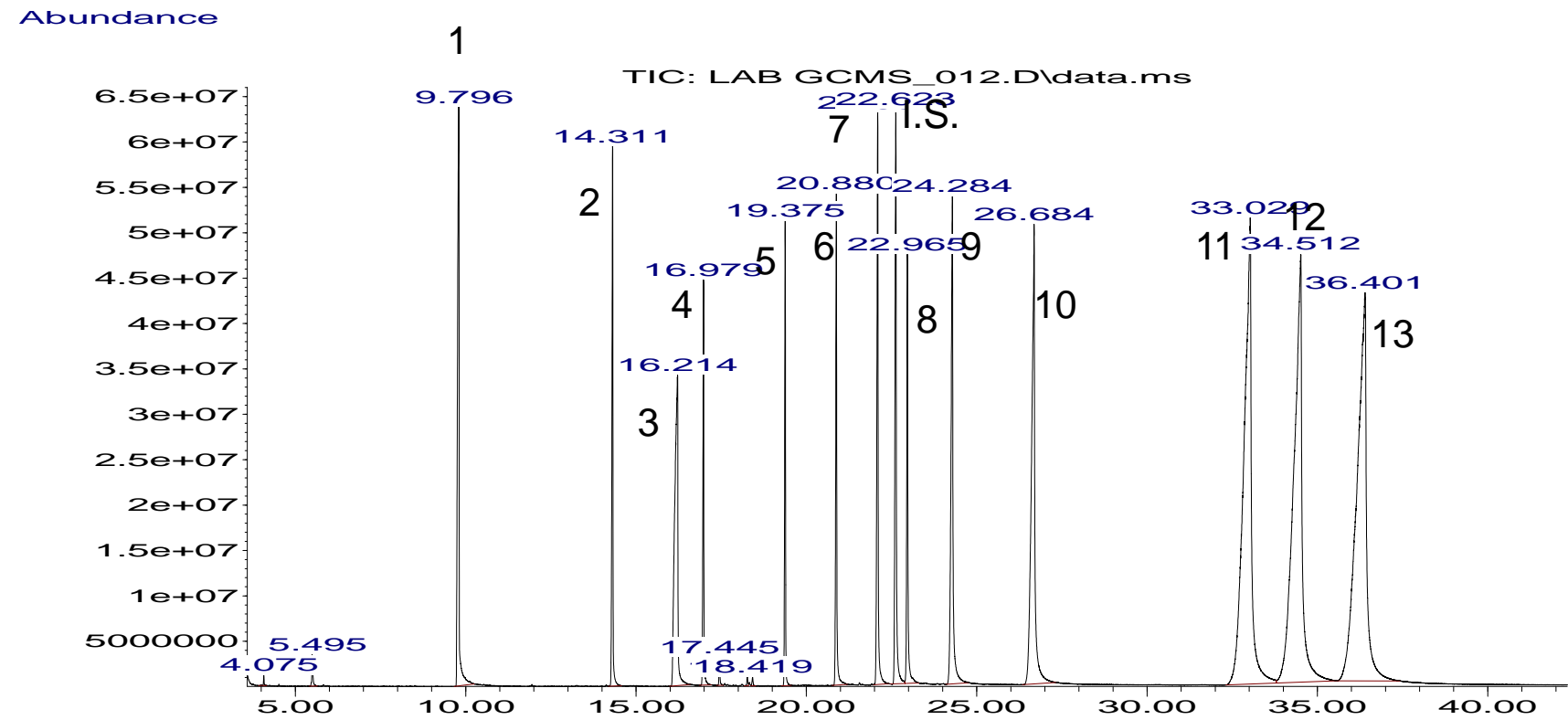

Time-->

Fig. (2). Total ion chromatogram of the coumarin mixture.
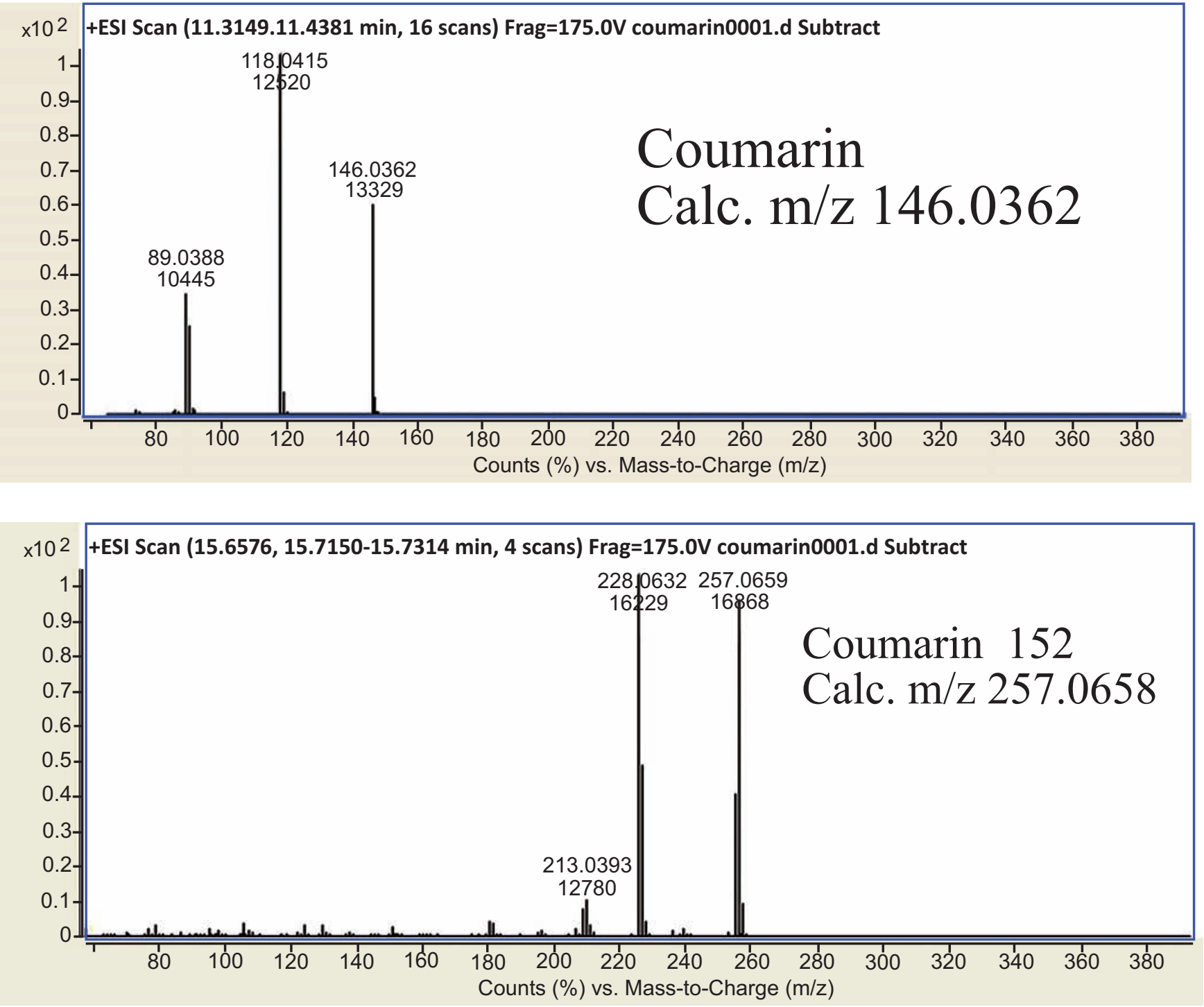

Fig. (3). Mass Spectra of Coumarin and Coumarin 152. 

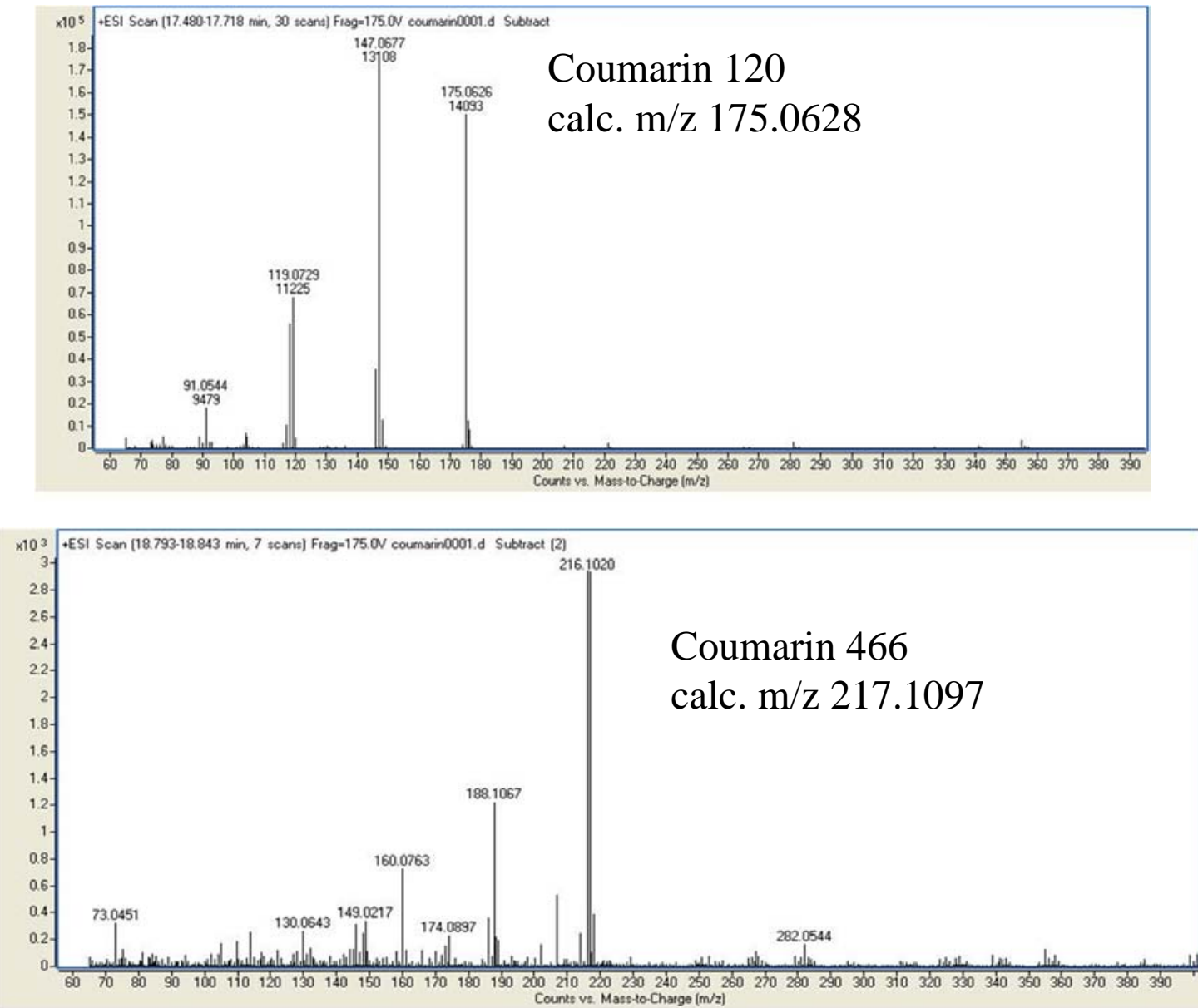

Fig. (4). Mass spectra of Coumarin 120 and 466.
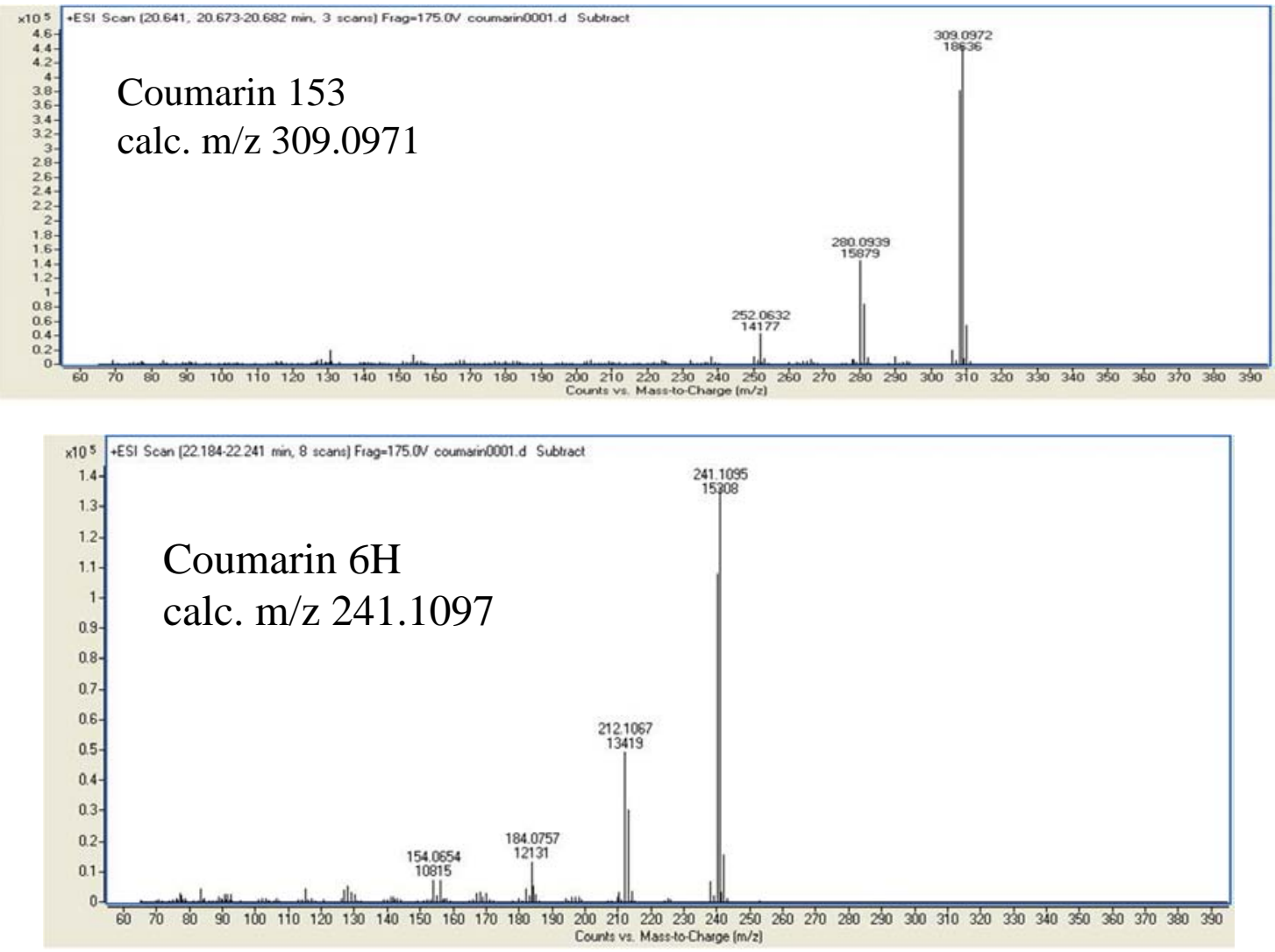

Fig. (5). Mass spectra of Coumarin 153 and 6H. 

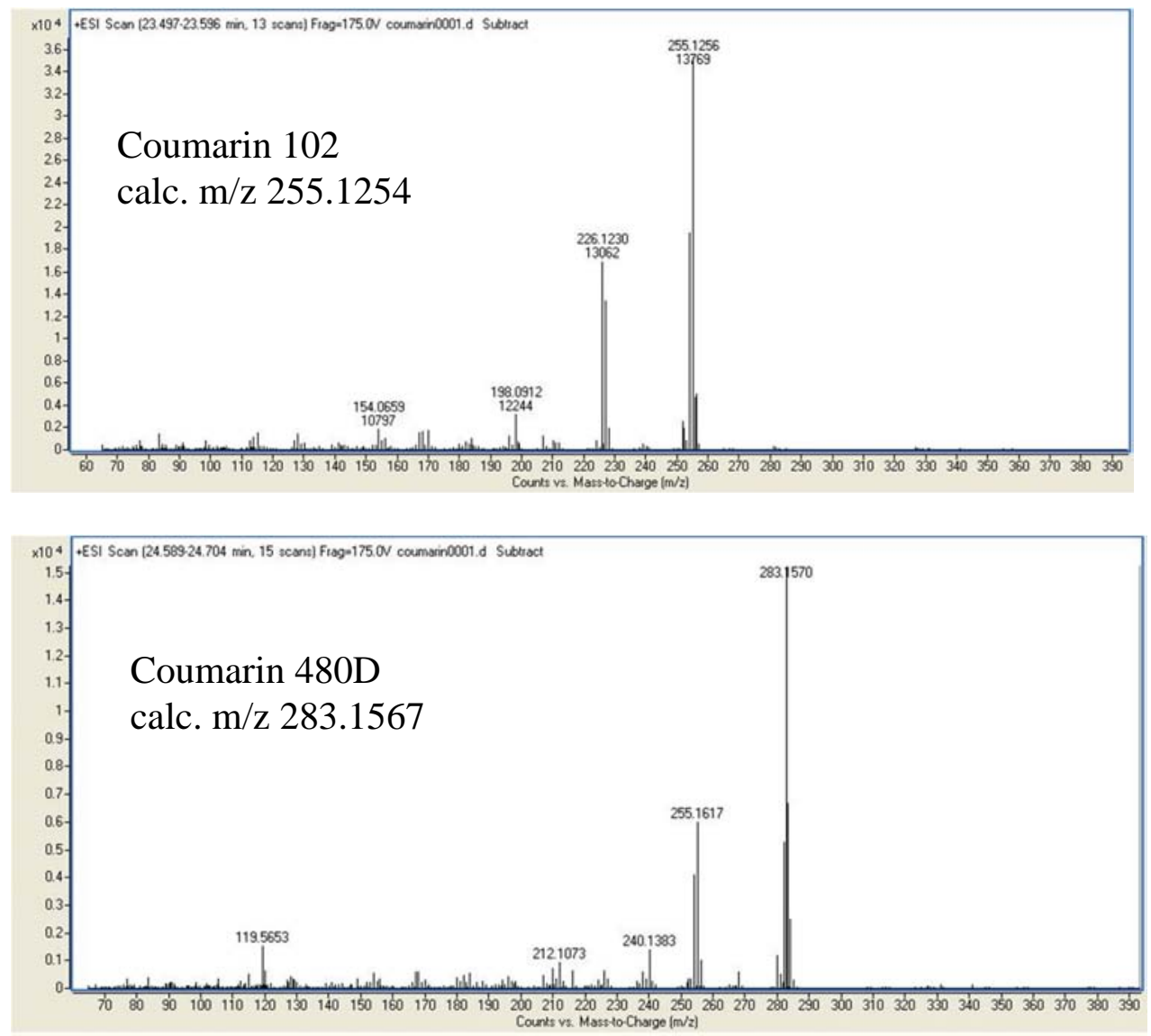

Fig. (6). Mass spectra of Coumarin 102 and 480D.
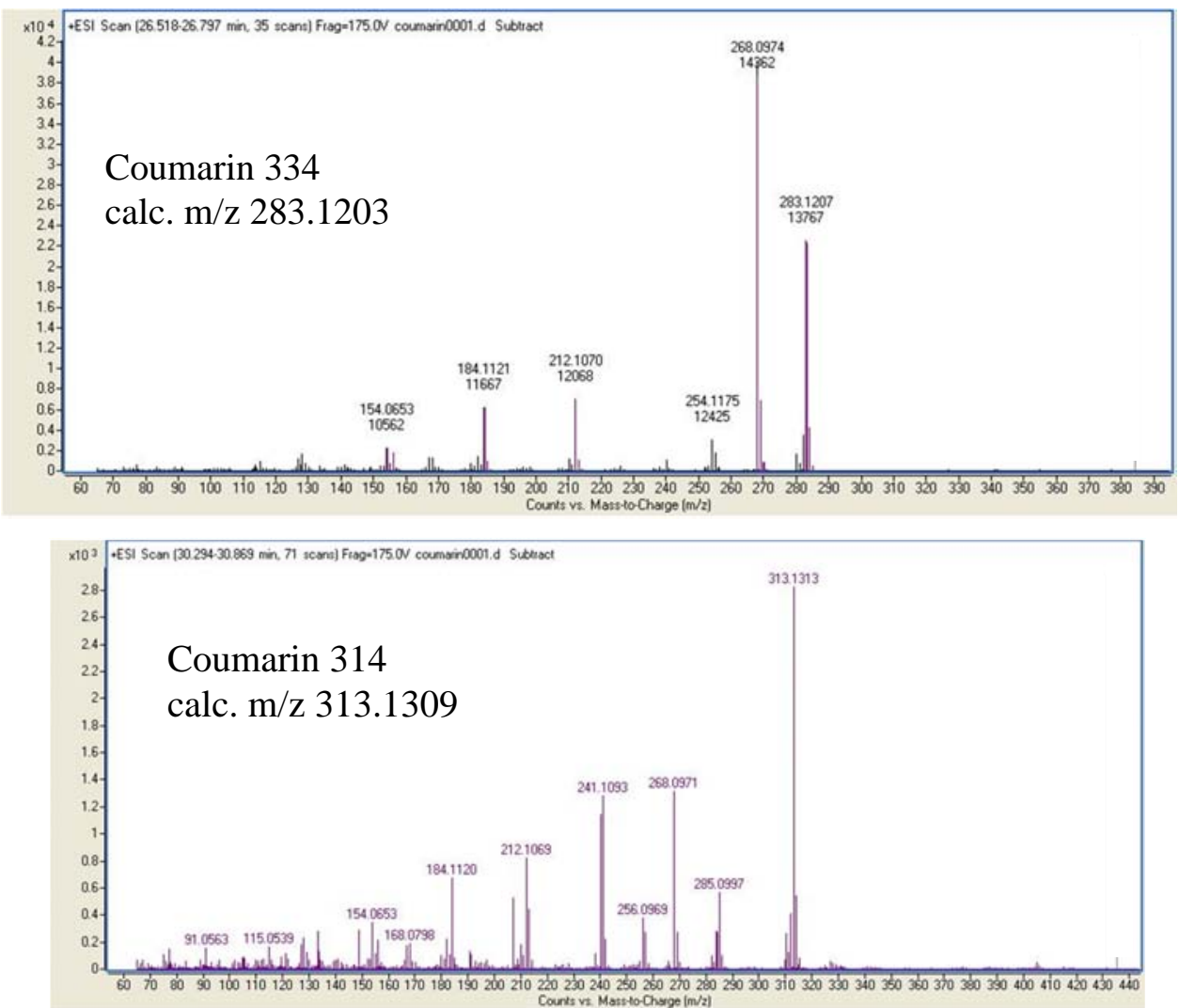

Fig. (7). Mass spectra of Coumarin 334 and 314. 

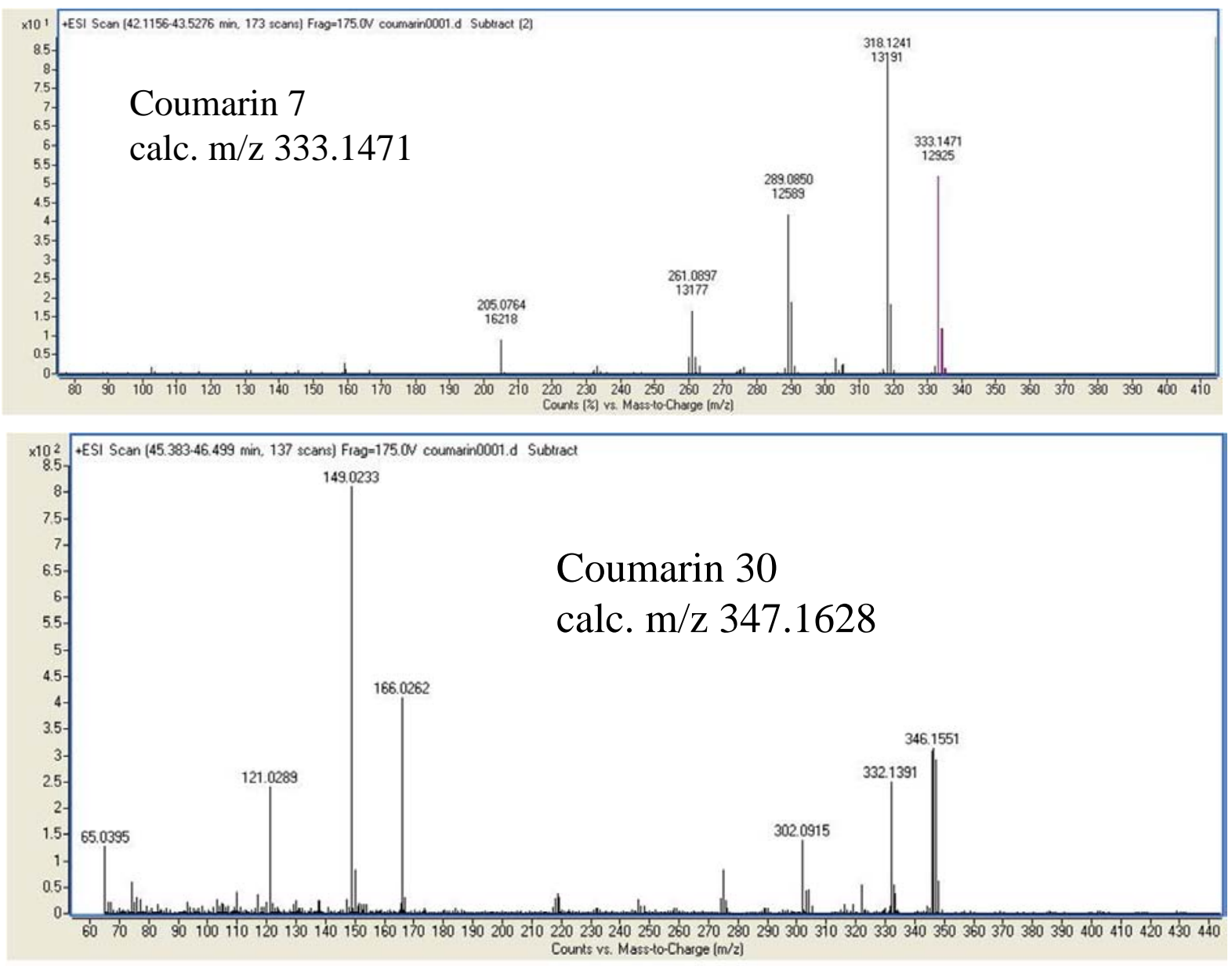

Fig. (8). Mass spectra of Coumarin 7 and 30.

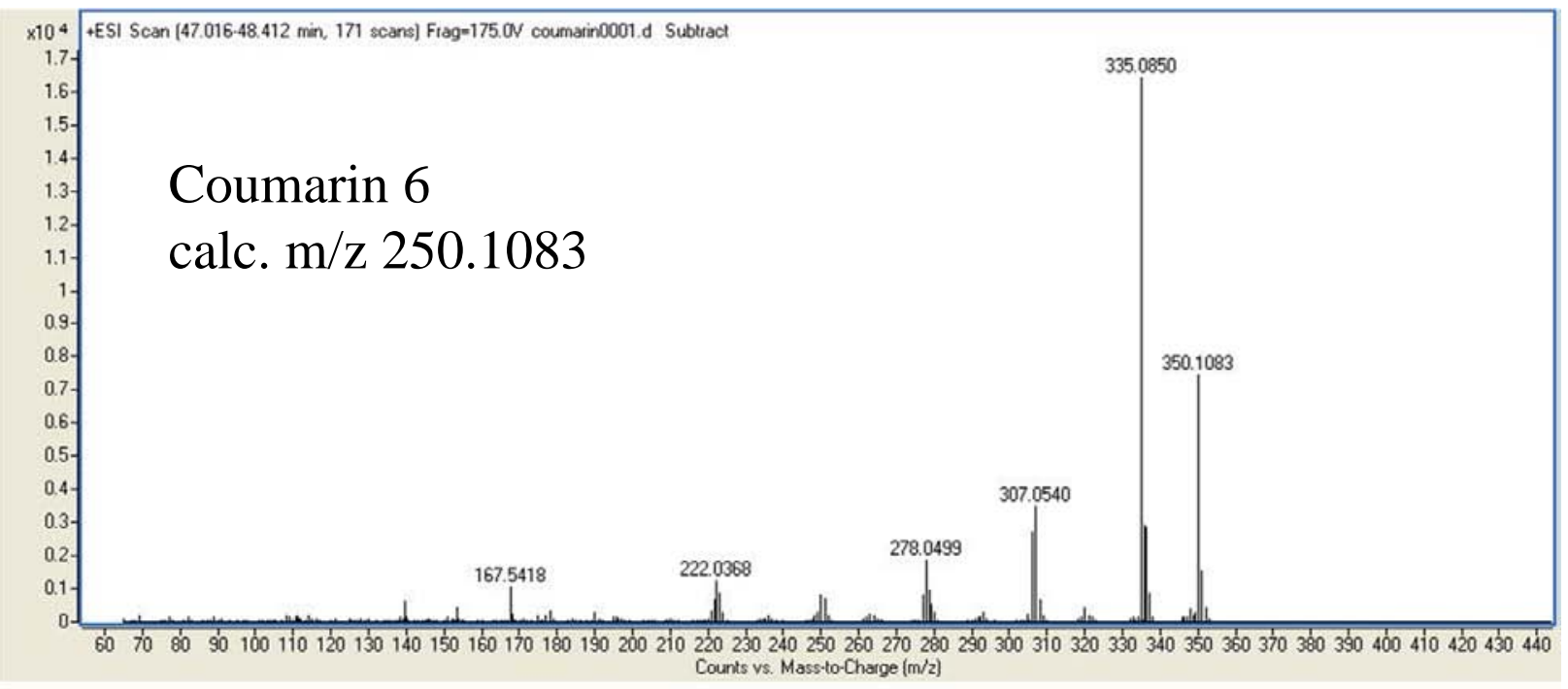

Fig. (9). Mass spectrum of Coumarin 6.

For Coumarin 30, which was ranked 4 out of 43 with scores between 85.18 and 37.88 , there were three molecular formulas with higher scores, all of which were "odd electron" ions, and had 6,10, and $10(\mathrm{r}+\mathrm{db})$, respectively. Molecular formula $\mathrm{C}_{16} \mathrm{H}_{21} \mathrm{~F}_{4} \mathrm{~N}_{3} \mathrm{O}$ with $6(\mathrm{r}+\mathrm{db})$ was eliminated from consideration because it had too few $(\mathrm{r}+\mathrm{db})$ and the other two possible molecular formulas, $\mathrm{C}_{14} \mathrm{H}_{18} \mathrm{FN}_{9} \mathrm{O}$ and $\mathrm{C}_{19} \mathrm{H}_{20} \mathrm{~F}_{3} \mathrm{~N}_{3}$ did not seem to fit because $\mathrm{C}_{14} \mathrm{H}_{18} \mathrm{FN}_{9} \mathrm{O}$ had too few $\mathrm{F}$ atoms and too many $\mathrm{N}$ atoms and $\mathrm{C}_{19} \mathrm{H}_{20} \mathrm{~F}_{3} \mathrm{~N}_{3}$ did not have any $\mathrm{O}$ atoms. 
<smiles>C/C=C(\C)N(C)C</smiles>

exp. $\mathrm{m} / \mathrm{z} 229.0708$

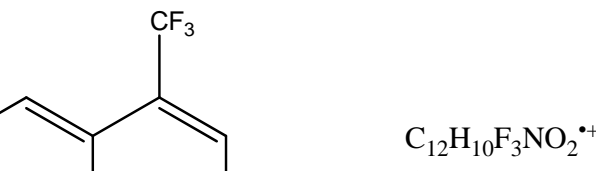

calc. $\mathrm{m} / \mathrm{z} 257.0658$

exp. $\mathrm{m} / \mathrm{z} 257.0659$<smiles>CCCCCCCC</smiles>

$$
\mathrm{C}_{11} \mathrm{H}_{9} \mathrm{~F}_{3} \mathrm{NO}^{+}
$$

calc. $\mathrm{m} / \mathrm{z} 228.0631$

exp. $\mathrm{m} / \mathrm{z} 228.0632$<smiles>[CH][N+](=C)c1ccc2c(C(F)(F)F)coc2c1</smiles>

$\mathrm{C}_{10} \mathrm{H}_{6} \mathrm{~F}_{3} \mathrm{NO}^{\bullet+}$

calc. $\mathrm{m} / \mathrm{z} 213.0396$

exp. $\mathrm{m} / \mathrm{z} 213.0393$

Fig. (10). EI fragmentation of Coumarin 152.

Coumarin $6 \mathrm{H}$ was ranked 2 . The first rank was given to molecular formula $\mathrm{C}_{10} \mathrm{H}_{15} \mathrm{~F}_{4} \mathrm{NO}$, which was easily eliminated from discussion because its mass spectrum showed two consecutive losses of $\mathrm{CO}$ and molecular formula $\mathrm{C}_{10} \mathrm{H}_{15} \mathrm{~F}_{4} \mathrm{NO}$ did not have enough $\mathrm{O}$ atoms.

\subsubsection{EI Fragmentation Patterns for Coumarins}

The fragmentation of the thirteen coumarins by EI - low resolution MS and EI- QTOFMS is very similar. This is not surprising because the EI source in both systems is the same and the QTOFMS was operated in the MS-only mode, but there was a slight possibility for post-source decay because of the collision chamber and we wanted to investigate that.

The coumarins investigated in this study fit into three groups. One group comprises Compounds 1-4 which have an alkyl or fluoroalkyl group on the pyrone ring at position 4 and an amino or alkyl amino group on the benzenoid ring at position 7. A second group comprises Compounds 5-10 with various alkyl or fluoroalkyl groups, a ketone or an ester group in the pyrone ring, and a quinolizidine ring attached to the benzenoid ring. The third group comprises coumarins with a benzimidazole or benzothiazole group at position 3 on the pyrone ring and a diethylamino group at position 7 on the benzenoid ring.
The EI QTOF spectra are given in Figs. (3-9). Major observations about the fragmentation of the coumarins in all three groups under EI conditions include:

a. ready elimination of $\mathrm{CO}$ from the molecular ion of alkyl-, fluoroalkyl-, and dialkylamino-coumarins to give the corresponding benzofuran "odd electron " ions is often followed by a second elimination of $\mathrm{CO}$ to give a substituted tropylium ion. (Fig. 10 shows the proposed fragmentation of Coumarin 152, which has a $\mathrm{CF}_{3}$ in position 4 and a dimethylamino group in position 7).

b. elimination of $\mathrm{CO}$ from the molecular ion may happen in parallel or is preceded by the elimination of $\mathrm{H} \cdot$ to give the $(\mathrm{M}-\mathrm{H})^{+}$ion especially when an electron-withdrawing functional group such as $\mathrm{CF}_{3}$ is present on the pyrone ring. It is interesting to note that, in the case of Coumarin 120 (Fig. 4), an alkyl group in position 4 will not cause the formation of the $(\mathrm{M}-\mathrm{H})^{+}$ion because the alkyl group is an electrondonating group, but when the alkyl group is attached to $\mathrm{N}$ on the benzenoid ring of Coumarin 466 (Fig. 4) it appears to stabilize the $(\mathrm{M}-\mathrm{H})^{+}$carbocation by its electron-donating inductive effect (2). 


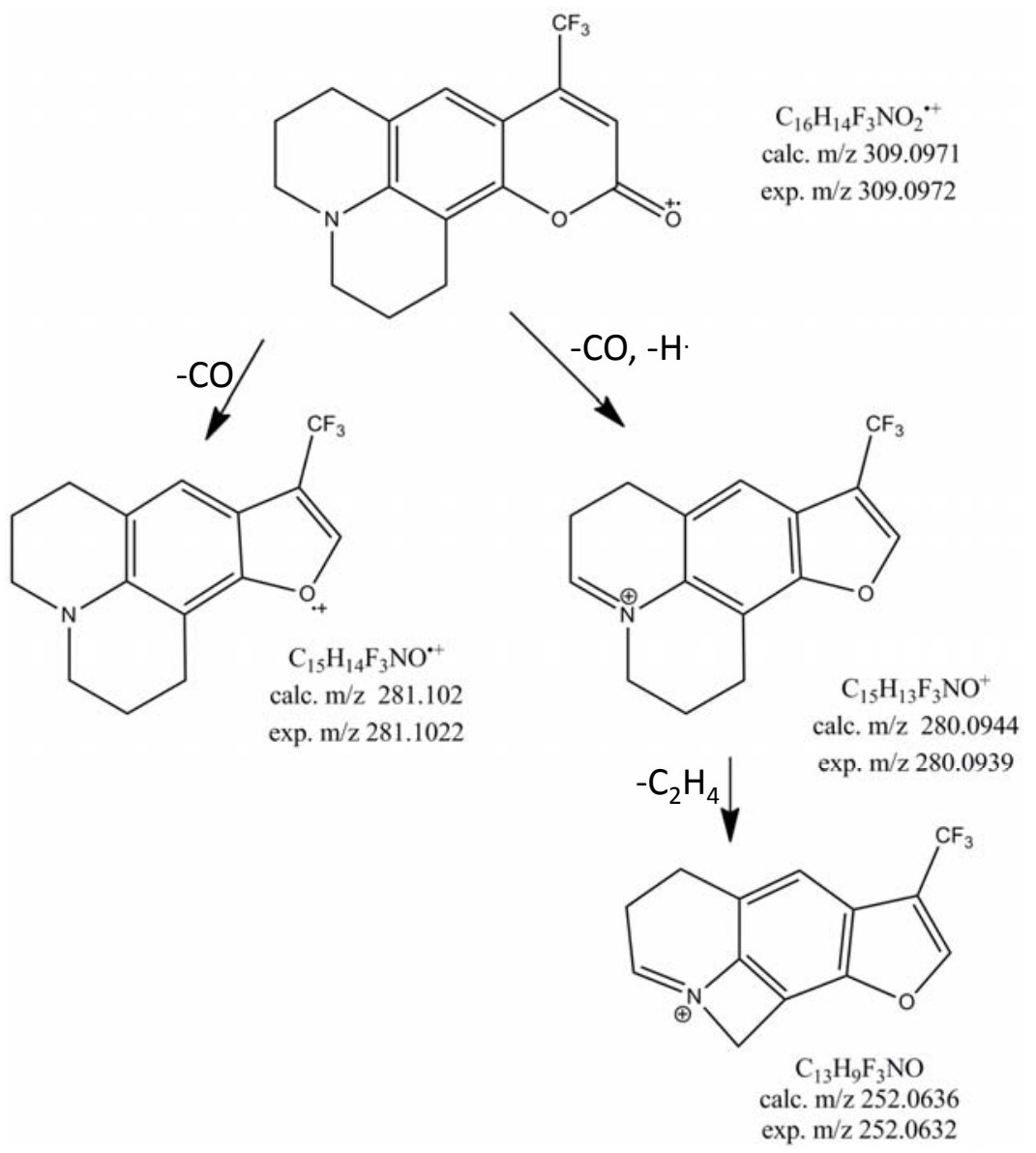

Fig. (11). EI fragmentation of Coumarin 153.

c. Quinolizidine-substituted coumarins 153, 6H, 102, and 480D give strong molecular ions and strong (M$\mathrm{H})^{+}$ions (see Fig. 11 for proposed fragmentation of Coumarin 153). Loss of CO from the $(\mathrm{M}-\mathrm{H})^{+}$ion is followed by a loss of $\mathrm{C}_{2} \mathrm{H}_{4}$ in Coumarins $153,6 \mathrm{H}$ and 102 to give the ion at $\mathrm{m} / \mathrm{z} 252.0632,184.0757$, and 198.0912, respectively. The mass spectrum of Coumarin 480D shows a loss of a methyl group from the ion at $\mathrm{m} / \mathrm{z} 255.1617$ which results in the ion at $\mathrm{m} / \mathrm{z}$ 240.1383. Subsequent loss of $\mathrm{C}_{2} \mathrm{H}_{4}$ from this ion accounts for the ion at $\mathrm{m} / \mathrm{z} 212.1073$. The presence of a carbonyl group on the pyrone ring in Coumarins 334 and 314 reduced significantly the elimination of $\mathrm{H}$ radical. Coumarin 334 showed a loss of $\mathrm{CH}_{3}$ to form ions at $\mathrm{m} / \mathrm{z} 268.0974$ while Coumarin 314 showed a loss of $\mathrm{C}_{2} \mathrm{H}_{4}$ to form the ion at $\mathrm{m} / \mathrm{z}$ 285.0997.

d. when benzimidazole and benzothiazole are attached to the pyrone ring at position 3 , the mass spectra of Coumarines 7, 30 and 6 (Figs. 8, 9) exhibit fragment ions resulting from the loss of alkyl substituents on the side groups on the benzenoid ring. For example, Coumarin 7, which has a diethylamino group at position 7 of the benzenoid ring and a benzimidazole group at position 3 in the pyrone ring, loses a methyl group to form the ion at $\mathrm{m} / \mathrm{z} 318.1241$ and then an ethyl group to form the ion at $m / z$ 289.0851 (Fig. 8). It is interesting to note that the ion at $\mathrm{m} / \mathrm{z} 318.1241$ loses $\mathrm{C}_{2} \mathrm{H}_{5}$ and not $\mathrm{CO}$ and $\mathrm{H}$ as would have been expected from the fragmentation pattern of coumarins substituted with small alkyl groups. After the loss of $\mathrm{C}_{2} \mathrm{H}_{5}$ or $\mathrm{C}_{2} \mathrm{H}_{4}$ from the diethylamino group, as in the case of Coumarin 6 (i.e., fragment ion at $\mathrm{m} / \mathrm{z}$ 335.0850 loses $\mathrm{C}_{2} \mathrm{H}_{4}$ or $\mathrm{C}_{2} \mathrm{H}_{5}$ to form ions at $\mathrm{m} / \mathrm{z}$ 307.0540 and 306.0461, respectively), a loss of $\mathrm{CO}$ and $\mathrm{H}$ to give the ion at $\mathrm{m} / \mathrm{z} 278.0501$ is followed by another loss of $\mathrm{CO}$ and $\mathrm{CH}_{2} \mathrm{~N}$ to form the ion at $\mathrm{m} / \mathrm{z} 222.0367$.

e. Loss of a $3^{\text {rd }} \mathrm{CO}$ group was found in the spectra of Coumarin 334 and Coumarin 314, which have $\mathrm{COCH}_{3}$ and $\mathrm{COOC}_{2} \mathrm{H}_{5}$ side chains, respectively. Coumarin 334 shows a loss of $\mathrm{CH}_{3}$ from the molecular ion to form the ion at $\mathrm{m} / \mathrm{z}$ 268.0974, which subsequently loses two $\mathrm{CO}$ to give the ion at $\mathrm{m} / \mathrm{z}$ 212.1070. The ion at $\mathrm{m} / \mathrm{z}, 254.1176$ is formed by loss of $\mathrm{CO}$ and $\mathrm{H}$ radical from the molecular ion. The ion at $\mathrm{m} / \mathrm{z}, 184.1121$ is the result of a CO loss from the ion at $m / z 212.1070$ and is present in both Coumarin 334 and 314 (see Fig. 7). Coumarin 314 loses $\mathrm{OC}_{2} \mathrm{H}_{5}$ to give a fragment ion at $\mathrm{m} / \mathrm{z}$ 268.0971, which subsequently loses $2 \mathrm{CO}$ to give ions at $\mathrm{m} / \mathrm{z} 212.1069$ or $3 \mathrm{CO}$ to give ions at $\mathrm{m} / \mathrm{z} 184.1120$. This is in agreement with an EI fragmentation pathway that was reported for 3-methoxycarbonyl coumarin except that instead of the ethoxy group, a methoxy group was eliminated first [6]. 


\section{CONCLUSIONS}

We have found that the EI fragmentation of coumarins when using a QTOFMS operated in MS-only mode is similar to that in a typical quadrupole mass spectrometer. We also demonstrated how our software is used to generate molecular formulas from high resolution accurate mass measurements including isotope ratio information, and how the number of rings and double bonds can be used to eliminate possible molecular formula assignments. Furthermore, we have shown that only with a high-resolution MS can one distinguish between the loss of $\mathrm{CO}, \mathrm{C}_{2} \mathrm{H}_{4}$, or $\mathrm{CH}_{2} \mathrm{~N}$. Finally, we learned that in order to identify a compound, one must first know with certainty which is the molecular ion, and this topic will be addressed in a separate publication.

\section{ACKNOWLEDGEMENTS}

The authors thank Simina Ticau, summer intern, for preparation of the standard solutions of test coumarins and for performing the GC- low resolution MS analysis. They also thank Noah Goldberg for technical review of the manuscript prior to publication.

\section{REFERENCES}

[1] Porter, Q.N. Mass Spectrometry of Heterocyclic Compounds, 2nd ed.; John Wiley \& Sons, New York, 1985.

[2] Kutney, J.P.; Eigendorf, G.; Inaba, T.; Dreyer, D.L. Mass Spectral Fragmentation Studies in Monomeric and Dimeric Coumarines. Org. Mass Spectrom., 1971, 5, 249-263.

[3] Mohamed, S.M. Electron Impact Ionization Mass Spectra of Fused Coumarino-4,3-d)-Pyrimidine Derivatives. Bull. Chem. Technol. Macedonia, 2005, 24(2), 117-126.

[4] Concannon, S.; Ramachandran, V. N.; Smyth, W.F. A Study of the Electrospray Ionization of Selected Coumarin Derivatives and their Subsequent Fragmentation using an Ion Trap Mass Spectrometer. Rapid Commun. Mass Spectrom., 2000, 14, 1157-1166.

[5] Concannon, S.; Ramachandran, V. N.; Smyth, W.F. A Study of the Electrospray Ionization and Ion Trap Fragmentation of Hemiterpenoid and Dimeric Coumarin Derivatives. Rapid Commun. Mass Spectrom., 2000, 14, 2260-2270.

[6] El-Deen, I.M.; Ibrahim, H.K. Synthesis and Electron Impact Mass Spectra of Substituted Chromeno[3,2-c]chromen-6,7-diones. Chem. Papers, 2004, 58(3), 200-204. 